\title{
Intermediary Metabolism Disorder
}

National Cancer Institute

\section{Source}

National Cancer Institute. Intermediary Metabolism Disorder. NCI Thesaurus. Code C97091.

An inborn metabolic disorder affecting the intermediary metabolism process. It results in accumulation of substances in the body that can cause acute or chronic intoxication. 